\title{
CORRECTION
}

\section{Correction: Kinome-wide analysis of the effect of statins in colorectal cancer}

Sarah Ouahoud, Rutger J. Jacobs, Maikel P. Peppelenbosch (D, G. M. Fühler, Jarom Heijmans, Sander Diks, Manon E. Wildenberg, Lukas J. A. C. Hawinkels, Liudmila L. Kodach, Philip W. Voorneveld (D) and James C. H. Hardwick

British Journal of Cancer (2021) 125:144; https://doi.org/10.1038/s41416-021-01426-6

Correction to: British Journal of Cancer https://doi.org/10.1038/ s41416-021-01318-9, published online 19 March 2021
The original version of this article unfortunately contained a mistake in an author name. Lucas J. A. C. Hawinkels should be Lukas J. A. C. Hawinkels. The authors apologize for the oversight. The original article has been corrected. 